\title{
A 50-yr-old female with cough and exertional breathlessness
}

\section{Case report}

A 50-yr-old female primary school teacher presented with a 4-month history of cough, productive of scanty mucoid sputum without any haemoptysis. Her general practitioner had treated her with antibiotics, inhaled steroids and inhaled bronchodilators without effect. She then gradually developed progressive exertional breathlessness, particularly on climbing stairs. There was a history of occasional wheezing. She denied any history of nocturnal cough, orthopnoea or ankle swelling. She also complained of tiredness but no weight loss. There was no history of eye, joint or skin problems. The patient was a life-long non-smoker with no history of exposure to industrial dust or asbestos. She kept a dog but never kept birds. There was no history of recent foreign travel.

\section{Examination}

On examination, she was comfortable at rest. There was no tachypnoea, finger clubbing, lymphadenopathy or cyanosis. The jugular venous pressure was normal and there was no ankle oedema. Her heart rate was 80 beats. $\mathrm{min}^{-1}$ and regular, and heart sounds were normal. Respiratory system examination revealed no tracheal deviation and normal percussion notes bilaterally. On auscultation, there were scanty crackles and occasional wheezes, particularly on the right mid zone. The remainder of the physical examination was normal. Oxygen saturation was $94 \%$ on air and she desaturated to $88 \%$ on exercise.

\section{Investigations}

Initial investigations revealed the following: haemoglobin $169 \mathrm{~g}^{-\mathrm{L}^{-1}}$; white cell count $16.5 \times 10^{9} \cdot \mathrm{L}^{-1}$ with neutrophilia; platelets $327 \times 10^{9} \cdot \mathrm{L}^{-1}$; and erythrocyte sedimentation rate 53 . The patient's renal function and electrolytes including calcium were normal. Liver function tests were normal, lactate dehydroge- nase was $904 \mathrm{U} \cdot \mathrm{L}^{-1}$, anti-nuclear antibodies and rheumatoid factor were negative, and serum angiotensin convertase was $30 \mathrm{U} \cdot \mathrm{L}^{-1}$.

Chest radiography was performed (fig. 1).

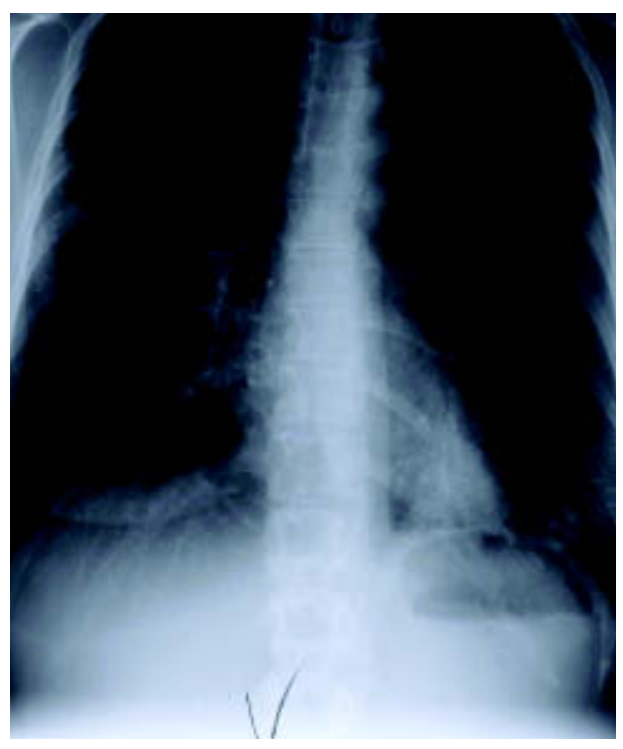

Fig. 1. - Chest radiography.

Task 1. Interpret the chest radiograph

\section{S. Mukherjee ${ }^{1}$ \\ K.K. Nanda \\ D.M. Green ${ }^{3}$ \\ P.A. Beckett ${ }^{1}$}

Depts of ${ }^{1}$ Respiratory Medicine, ${ }^{2}$ Radiology and ${ }^{3}$ Histopathology Queen's Hospital Burton-upon-Trent

UK

\section{Correspondence:}

S. Mukherjee

Queen's Hospital

Belvedere Road

Burton-upon-Trent

Staffordshire

DE13 ORB

UK

Fax: 441283593129

E-mail:

smukherjee66@yahoo.com 


\section{Answer 1.}

The chest radiograph showed widespread interstitial shadowing bilaterally with rightsided predominance. There were septal lines (Kerley $A$ and $B$ ) in the affected parts with some nodularity at places in both lower and midzones on the right side.

A range of pulmonary function tests were performed and are presented in table 1 .

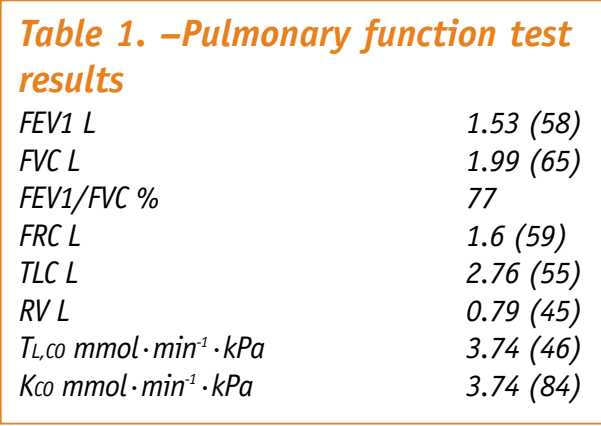

Data in parenthesis indicate per cent predicted. FEV1: forced expiratory volume in one second; FVC: forced vital capacity; FRC: functional residual capacity; RV: residual volume; TLC: total lung capacity; $T L, c o:$ transfer factor of the lung for carbon monoxide; Kco: carbon monoxide transfer coefficient.

A high-resolution CT scan of chest (fig. 2) was also carried out.

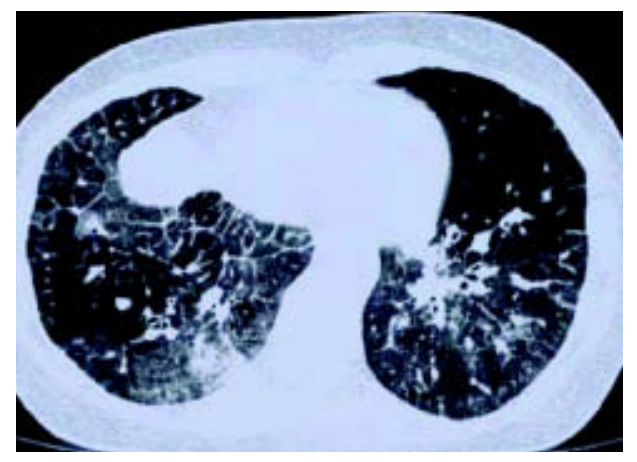

Fig. 2. - HRCT of the chest.

\section{Task 2.} Interpret the HRCT scan

\section{Answer 2.}

The HRCT showed marked peripheral pulmonary opacities bilaterally, predominantly on the right side and left lower lobe. The diffuse alveolar opacities extended to the periphery and caused pleuro-pulmonary tails at places. Some of the opacities were confluent and formed a nodule-like appearance in both lower lobes and right middle lobe. The appearances are highly suggestive of bronchoalveolar cell carcinoma. There is a relative lack of subpleural space disease with no areas of cystic change. There is no evidence of extra-pulmonary disease.

Bronchoscopy showed no endobronchial pathology but transbronchial biopsies from right middle lobe showed atypical epithelial nests embedded in fibrotic stroma with a squamoid appearance, and these cells were positive for cytokeratins (AE1/AE3, cytokeratins 5/6). Tru-cut needle biopsies of the right lung under CT guidance were also obtained (fig. 3).

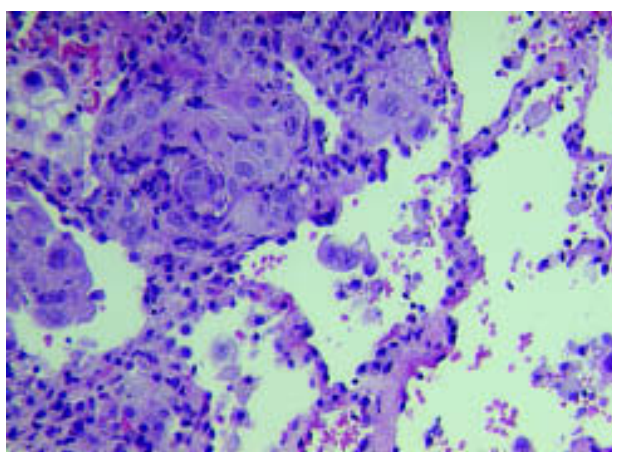

Fig. 3. - Tru-cut needle biopsies of the right lung

Task 3.

Interpret the histopathological results 


\section{Answer 3.}

The biopsy showed extensive infiltration of lung tissue by poorly differentiated squamous cell cancer. No keratin pearl formation was identified but all the cells were of squamoid appearance and distinct intercellular desmosomes were identifiable in several areas. In some areas, the tumour had excited a moderate desmoplastic stromal reaction but alveolar wall fibrosis was strictly limited to those areas involved by tumour.

The patient had a rapidly progressive downhill course and died within 2 weeks of diagnosis.

Task 4.

Suggest a diagnosis.

\section{Answer 4.}

Squamous cell lung cancer presenting as diffuse alveolar and interstitial infiltrates.

\section{Discussion}

The World Health Organisation (WHO) proposed a pathological classification system for lung cancer in 1999 [1]. Amongst the nonsmall cell lung cancers (NSCLC), squamous and adenocarcinoma account for most of the cases. Squamous cell cancer (SCC), which accounts for $30-40 \%$ of all lung cancers, typically (60\%) arises in the central bronchi, and commonly extends into the hilum and mediastinum. It may also occur in the lung parenchyma where it may cavitate [2]. The diffuse and multilobar involvement in this patient is extremely unusual and to our knowledge this is only the second report of such a case [3], and the first in a non-smoking patient. Whilst the biopsies showed prominent fibrosis, this was seen only in the vicinity of the tumour, making it unlikely that the carcinoma had arisen from a background of diffuse interstitial fibrosis. Moreover, the CT scan did not suggest diffuse fibrosis.

Although lung cancers tend to develop as nodular masses, one particular subtype, known as bronchoalveolar carcinoma, does exhibit heterogeneity and is well known to occur in a diffuse and/or multifocal pattern [4]. This distinct type of primary lung cancer may be a subtype of adenocarcinoma and is the least common type of primary lung cancer, although the incidence appears to be increasing, particularly in non-smoking females [4,5]. It should be borne in mind that lung cancers are frequently heterogeneous and biopsy specimens provide only a small amount of tissue with which to make a diagnosis. Indeed, the WHO [1] classification of lung cancer is based upon differentiation in the whole tumour. It could be argued that our biopsies were not truly representative of the tumour. However, SCC can be diagnosed with a high degree of accuracy even in non-surgical specimens if diagnostic criteria for squamous differentiation (keratin, intercellular bridges) are strictly adhered to [6-7]. The histological appearances in this case were quite clearly indicative of a squamous origin.
"Squamous cell cancer should be included in the differential diagnosis of diffuse paranchymal lung disease." 
If you have an interesting case that you would like to submit to Breathe please go to: www.breathe-cme.org

\section{Conclusions}

SCC may present as a diffuse radiological infiltrate and should be included in the differential diagnosis of diffuse parenchymal lung disease. Diagnosis can be established by percutaneous lung biopsy.

\section{References}

1. Travis WD, Colby TV, Corrin B et al. Histological typing of lung and pleural tumours. 3rd ed. Berlin, Springer Verlag, 1999. (International histological classification of tumours 1).

2. Beckles MA, Spiro SG, Colice GL, Rudd RM. Initial evaluation of the patient with lung cancer: symptoms, signs, laboratory tests, and paraneoplastic syndromes. Chest 2003; 123 (Suppl): 97S-104S.

3. Meysman M, Schoors DF, Reynaert H, Noppen M, Pierre E, Vicken W. Respiratory failure with diffuse patchy lung infiltrates: an unusual presentation of squamous cell carcinoma. Thorax 1994; 49(12): 1271-1272.

4. Barkley JE, Green MR. Bronchioloalveolar carcinoma. J Clin Oncol 1996;1 4(8): 2377-386.

5. Dumont $P$, Gasser B, Rouge C, Massard G, Wihlm JM. Bronchoalveolar carcinoma: histopathologic study of evolution in a series of 105 surgically treated patients. Chest 1998; 113(2): 391-395.

6. Payne CR, Hadfield JW, Stovin PG, Barker V, Heard BE, Stark JE. Diagnostic accuracy of cytology and biopsy in primary bronchial carcinoma. J Clin Pathol 1981; 34(7): 773-778.

7. Edwards SL, Roberts C, McKean ME, Cockburn JS, Jeffrey RR, Kerr KM. Preoperative histological classification of primary lung cancer: accuracy of diagnosis and use of the non-small cell category. J Clin Pathol 2000; 53(7): 537-540. 